\title{
Ortodontia como atividade de meio ou resultado?
}

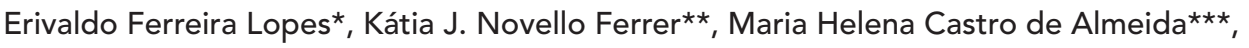

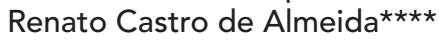

\section{Resumo}

Este trabalho apresenta a Ortodontia como atividade de meio, abordando as obrigações profissionais e as formas de se evitar e de se defender de ações judiciais. A grande parte dos litígios entre pacientes e ortodontistas se dá pelo fato equivocado, que ainda perdura, de que muitos juristas consideram a Ortodontia uma especialidade de fim, quando, na verdade, sua prática está sujeita a fatores que a caracterizam como atividade de meio. A Ortodontia deve ser, portanto, considerada uma obrigação de meio, onde o profissional tem o dever de utilizar todos os meios possiveis para atingir as expectativas do paciente, sem, entretanto, ter a obrigação de atingir o resultado idealizado. $\mathrm{O}$ ortodontista deve ser responsabilizado somente quando incorrer em imprudência, negligência, imperícia ou em caso de propaganda enganosa. Para evitar litígios, o ortodontista deve ter uma boa conduta profissional, registrando e mantendo arquivadas todas as etapas do tratamento, efetuando diagnósticos diferenciados, baseados nas características individuais, e escolhendo e conduzindo adequadamente o plano de tratamento.

Palavras-chave: Atividade de meio. Atividade de resultado. Processo judicial.

\section{INTRODUÇÃO}

O crescente número de ações judiciais contra ortodontistas no Brasil é um fato preocupante, principalmente a partir do advento do Código de Defesa do Consumidor, conforme Lei n. 8.078 de 11 de setembro de 1990. É perceptível a mudança no comportamento dos pacientes ortodônticos brasileiros que são usuários de serviço e buscam na justiça a reposição de um prejuízo sofrido ${ }^{22}$.

As obrigações de meio podem ser definidas como sendo uma espécie de comprometimento, que um contratante faz com um contratado, de prestar um serviço com o melhor de sua força física, mental e intelectual, bem como com a responsabilidade normal que se espera de um profissional qualificado para o desenvolvimento da tarefa contratada. Uma obrigação de meio indica que há um comprometimento de dedicação pessoal com vistas ao melhor resultado. Trata-se de uma obrigação subjetiva, onde um resultado final pode não corresponder totalmente ao esperado. As obrigações de resultado, ao contrário, seriam objetivas, tendo como obrigatoriedade o resultado proposto ${ }^{4,12,13}$.

\footnotetext{
* Mestre e doutorando em Ortodontia pelo C.P.O. São Leopoldo Mandic. Professor assistente de Ortodontia da FUNORTE/NE. Graduando em Direito pela UNESC/Campina Grande/PB.

** Especialista em Prótese Dentária e em Ortodontia pela UNICASTELO. Mestre em Odontologia pela UNICASTELO. Doutora em Ortodontia pela FOP/UNICAMP. Coordenadora e professora do programa de mestrado em Odontologia, área de Ortodontia, do C.P.O. São Leopoldo Mandic.

*** Especialista em Ortodontia pelo C.F.O. Doutora e livre-docente em Ortodontia pela FOP/UNICAMP. Professora do programa de mestrado em Odontologia, área de Ortodontia, do C.P.O. São Leopoldo Mandic. Professora do programa de doutorado em Odontologia, área de Ortodontia, do C.P.O. São Leopoldo Mandic.

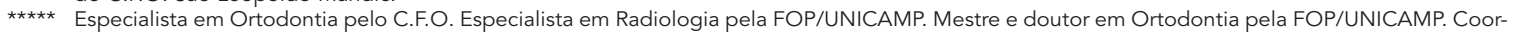
denador e professor do programa de mestrado em Odontologia, área de Ortodontia, do C.P.O. São Leopoldo Mandic. Professor do programa de doutorado em Odontologia, área de Ortodontia, do C.P.O. São Leopoldo Mandic.
} 
Alguns juristas entendem que sendo o ortodontista um profissional que depende, durante o tratamento proposto, de fatores biológicos e comportamentais de cada paciente, não poderia ser responsabilizado por fatores que independem de sua capacitação profissional ${ }^{14,19}$.

O propósito dessa revisão foi demonstrar que a Ortodontia deve ser encarada como atividade de meio.

\section{REVISÃO DE LITERATURA}

Demogue ${ }^{5}$ elaborou a "teoria da obrigação", na qual dividiu os profissionais em duas áreas de obrigação, sendo a primeira a obrigação de meio, onde o profissional deve, durante a execução de sua atividade, desempenhar o melhor possível de sua técnica em prol de seu cliente, porém, o resultado final independe de sua vontade. A exemplo do trabalho do advogado, que fica à mercê da sentença do juiz, algumas especialidades da área da Saúde também podem ser consideradas como de meio. Outros profissionais, no entanto, são incluídos na chamada obrigação de resultado, tendo assim o dever de atingir determinado resultado esperado e desejado pelo cliente, sob pena de processo.

Freqüentemente, o ortodontista é requisitado para emitir uma segunda opinião sobre um caso. Esta requisição pode ser sobre um tratamento que ainda não iniciou, sobre um em andamento ou ainda sobre o resultado final ${ }^{1}$. Quando requisitado, o profissional deve considerar que a sua opinião pode envolvê-lo numa ação litigiosa, isto é, um paciente insatisfeito poderá acionar não apenas o ortodontista clínico, mas também o que emitiu um segundo parecer. O profissional que julgar ter sua reputação prejudicada por uma segunda opinião sobre a sua conduta pode, também, abrir um processo contra quem provocou a polêmica.

Koubik e Feres ${ }^{8}$ estudaram as questões de ética e aspectos legais do ortodontista e destacaram as principais causas de litígios como sendo: a) reabsorção radicular, b) problemas periodon- tais; c) caninos retidos ou impactados d) articulação temporomandibular; e) doenças infecciosas no consultório odontológico; f) tratamento ortodôntico e aparência facial; g) utilização de braquete cerâmico e h) cuidados na fase pré-conclusão.

Os fatores que mais geram ações judiciais contra o ortodontista incluem, ainda: falta de registros com informações consistentes e sistemáticas sobre a condução do tratamento; erros de diagnóstico; erros na escolha do tipo de tratamento; falta de cuidados durante e após o tratamento; problemas de relacionamento entre profissional e paciente.

Santos ${ }^{17}$ escreveu um artigo sobre a obrigação de resultado do cirurgião-dentista, explicando que não é possível garantir um resultado, posto que cada organismo responde biologicamente de forma diferente de outro, ressaltando que não há obrigação legal para que o cirurgião-dentista atinja um resultado, conforme inciso II do Art $5^{\circ}$ da Constituição Federal (CF) que ressalta que ninguém será obrigado a fazer ou deixar de fazer nada se não em virtude da lei. Como não existe no Brasil uma lei onde o cirurgião-dentista seja obrigado a atingir resultado, este não pode ser condenado com base na "obrigação de resultado". Argumenta que também, como garante o Art. $5^{\circ}$ da Constituição Federal, somos todos iguais perante a lei, sem distinção de qualquer natureza e com direito à dignidade, conforme Art. $1^{\circ}$, inciso III da mesma CF. $\mathrm{O}$ autor conclui que exigir do cirurgião-dentista um resultado além de ilegítimo é aviltante a esta dignidade.

A responsabilidade do dentista situa-se no mesmo plano e sob as mesmas perspectivas da responsabilidade médica, não cabendo a esses profissionais assegurarem a cura, o resultado, mas sim aplicar toda diligência de sua técnica para atingila. Venosa ${ }^{20}$ citou as seguintes especialidades da Odontologia como sendo de obrigação de meio, ou seja, que não admitem que se assegure resultado: Traumatologia Buco-maxilo-facial, Endodontia, Periodontia, Odontopediatria e Ortodontia. 


\section{DISCUSSÃO}

A consideração da profissão do ortodontista como de meio ou de resultado é relevante para a apreciação de casos processuais contra o profissional, uma vez que a avaliação da culpa e da prova está diretamente relacionada com o tipo de obrigação assumida ${ }^{10}$.

Alguns autores ${ }^{4,5,6,7,21}$ consideraram a Odontologia como uma atividade que garante o resultado proposto no início do tratamento, e que esses profissionais devem reparar danos sofridos pelos pacientes. Por outro lado, outros autores ${ }^{11,12,14,17,19,20}$ ressaltaram que algumas especialidades da Odontologia, como a Traumatologia Buco-maxilo-facial, a Endodontia, a Periodontia, a Odontopediatria e a Ortodontia, não admitem que se assegure resultado e são, portanto, uma obrigação de meio.

Embora haja uma tendência dos juristas considerarem o tratamento ortodôntico como obrigação de resultado, existe uma grande divergência, uma vez que não há jurisprudência na área de Ortodontia. A prática processual vem apontando que profissionais que prestam serviços especiais não têm como garantir que seus clientes sejam amplamente satisfeitos nas empreitadas contratadas, devido às limitações biológicas envolvidas ${ }^{10,14,17}$.

Os fatores biológicos e a colaboração do paciente também podem interferir nos resultados do tratamento e devem ser considerados co-responsáveis pelos efeitos atingidos ao final da terapia ortodôntica ${ }^{11,18}$. Logo o sucesso do tratamento não é apenas dependente do conhecimento técnico-científico do profissional, mas também do conhecimento científico de terceiros, tal como dos fabricantes de materiais ${ }^{15}$. Considerando que as obrigações do ortodontista são tão subjetivas quanto o são para o paciente, cabe ao profissional agir conforme o padrão esperado para situações semelhantes, provando que foram utilizados todos os meios possíveis para atingir ou chegar o mais próximo possível do resultado esperado pelo paciente.
De acordo com o artigo 206 do Código Civil de 2002, o prazo para prescrição da reparação civil envolvendo profissionais liberais é de três anos ${ }^{3}$, e de cinco anos conforme o artigo 27 do Código de Defesa do Consumidor ${ }^{2}$. O tempo começa a contar após o profissional informar o paciente sobre as reais condições no pós-tratamento, incluindo os pontos positivos e falhas ocorridas, como espaços remanescentes, reabsorção radicular, descalcificação ${ }^{8}$. Portanto, a ficha clínica, modelos e demais peças comprobatórias devem ser guardados por cinco anos após o término do tratamento ortodôntico. Cuidados devem ser tomados em casos de contenção excessivamente prolongada, mantida com consultas obrigatórias, que podem tornar o profissional responsável por um maior tempo.

O ortodontista pode minimizar sua taxa de risco profissional, evitando ações por parte de seus pacientes. Para tanto, deve munir-se de uma série de atenções e cuidados, mantendo-se muito bem documentado sobre o antes, o durante e o pós-tratamento. A observância rigorosa das regras da boa atuação profissional e a prática sistemática de um bom relacionamento, onde impere a harmonia e a amizade com seus pacientes, também contribuirão para o sucesso profissional sem ações litigiosas desgastantes ${ }^{9}$.

Santos $^{17}$ diz que considerar a atividade do cirurgião-dentista uma obrigação de resultado é uma afronta à Constituição Federal e ninguém se levanta contra! Por quê? É conveniente que o cirurgião-dentista se veja obrigado a contratar um seguro de responsabilidade civil, mesmo com as limitações de cobertura que as apólices contêm? Devemos provocar as modificações primeiro em nós, mudando nossos conceitos.

A nossa opinião coincide, ipsis literis, com San$\operatorname{tos}^{17}$, pois não existe lei específica sobre a questão, uma vez que o ordenamento jurídico no Brasil mostra com clareza essa incoerência entre o atual entendimento dos juristas e o que diz nossa Constituição Federal. Para se compreender a forma como as normas jurídicas se estruturam e se cor- 


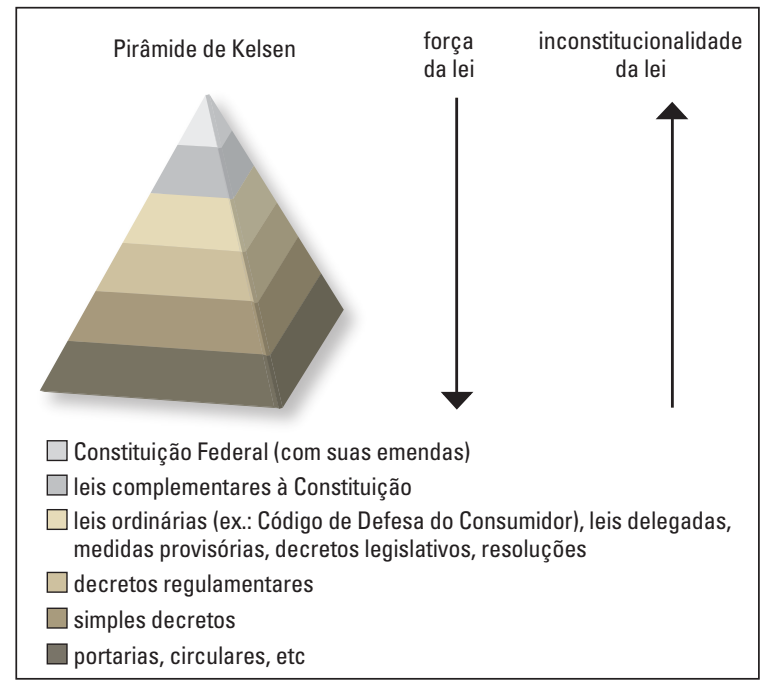

FIGURA 1 - 0 ordenamento jurídico e a hierarquia das normas: a Pirâmide de Kelsen (Fonte: KELSEN ${ }^{23,24}$ ).

relacionam, deve-se ter em mente que nenhuma norma tem existência isolada, independente, solitária. Ao contrário, as normas jurídicas convivem umas com as outras, se entrelaçam, se complementam, se ajustam reciprocamente, conjugando-se de forma harmoniosa (Fig. 1).

Existem, portanto, dois fluxos, um ascendente e outro descendente. Pelo fluxo ascendente, partindo-se de determinada norma, ela deve fundamentar-se em outra norma superior e esta em outra norma situada num patamar mais elevado e assim sucessivamente, até se chegar à última instância, a uma norma básica que é a Constituição, denominada norma fundamental, por servir de fundamento para todo o sistema. De igual modo, pelo fluxo descendente, estabelece-se uma linha de descendentes sucessivos, que são as normas fundadas, tendo todas elas uma ascendente comum, que é a norma fundamental. O fluxo ascendente sinaliza a fundamentação; o fluxo descendente a derivação.

Em conseqüência disso, para que uma norma seja válida, deve respeitar o conteúdo da norma jurídica superior.

Por fim, como entender uma decisão jurídica baseada no Código de Defesa do Consumidor, Lei n. 8.078, de 11 de setembro de 1990, que diz que o prazo para prescrição de reparação civil envolvendo profissionais liberais é de cinco anos, no seu artigo 22 e, de acordo com o artigo 206 do Código Civil, lei n. 10.406, de 10 de janeiro de 2002, que versa sobre o mesmo assunto é de 3 anos $^{3}$ ?

\section{CONCLUSÃO}

Após revisar e discutir os assuntos contidos na bibliografia, julgamos ser legítimo concluir que a Ortodontia deve ser considerada uma atividade de meio porque não tem obrigação de resultado. O resultado do tratamento ortodôntico não depende somente do profissional, sendo dependente da cooperação do paciente e também de fatores biológicos e psicológicos individuais, que podem limitar a ação da terapêutica ortodôntica. O ortodontista pode ser responsabilizado civilmente somente quando incorrer em imprudência, negligência, imperícia ou propaganda enganosa. 


\title{
Orthodontics as a support or core activity?
}

\begin{abstract}
This study presents Orthodontics as a support activity, approaching professional obligations and ways to avoid and defend against legal action. A considerable part of litigation between patients and orthodontists results from the mistaken fact, which still persists, that many scholars regard Orthodontics as a core activity. In reality, its practice is subjected to factors that characterize it as a support activity. Orthodontics must be, therefore, regarded as a support obligation, whereupon the professional has the obligation to make use of all means possible to meet the patient's expectations - without, however, having the obligation to achieve the idealized result. The orthodontist must be made responsible only upon acts of imprudence, negligence, malpractice, or in the case of false advertising. In order to avoid litigation, orthodontists must have good professional conduct, registering and filing all stages of the treatment, performing differential diagnostics, based on individual characteristics, and adequately choosing the treatment plan.
\end{abstract}

Key words: Support activity. Result activity. Litigation.

\section{REFERÊNCIAS}

1. BOWERS, S. A. Second opinions. Am. J. Orthod. Dentofacial Orthop., St. Louis, v. 97, no. 3, p. 269-270, Mar. 1990

2. BRASIL. Código de defesa do consumidor: lei $n^{\circ} 8.078$, de 11 de setembro de 1990. 11. ed. São Paulo: Atlas, 1999.

3. BRASIL. Novo Código Civil brasileiro: lei $n^{\circ} 10.406$, de 10 de janeiro de 2002. 3. ed. São Paulo: R. dos Tribunais, 2003.

4. CALVIELLI, I. T. P. O código de defesa do consumidor e o cirurgião-dentista como prestador de serviços. In: SILVA, M. Compêndio de Odontologia Legal. São Paulo: Medsi, 1997.

5. DEMOGUE, R. La classification des obligations determinées (où de resultat) et obligations génerales de prudence et diligence (où des moyens). 5e. éd. Paris: [s.n.], 1926.

6. DIAS, J. A. Da responsabilidade civil. Rio de Janeiro: Forense, 1983.

7. GIOSTRI, H. T. Erro médico: a luz da jurisprudência comentada. Curitiba: Juruá, 1998.

8. KOUBIK, R.; FERES, M. A. L. Aspectos legais da Ortodontia. Ortodontia, São Paulo, v. 28, no. 2, p. 64, 70, maio/ago. 1995.

9. MACHEN, D. E. Legal aspects of orthodontic practice: risk management concepts. Treatment records and the defensible case. Am. J. Orthod. Dentofacial Orthop., St. Louis, v. 96, no. 2, p. 173-175, Aug. 1989.

10. MACHEN, D. E. The need for a structured dismissal program. Am. J. Orthod. Dentofacial Orthop., St. Louis, v. 97, no. 2, p. 176-177, 1990.

11. MALACARNE, G. B.; SILVA, A. A. Natureza da relação profissional/paciente e do contrato. JBO, Curitiba, v. 4, n. 23, p. 424-429, set. 1999.

12. OLIVEIRA, M. L. L. Responsabilidade civil odontológica. Belo Horizonte: Del Rey, 2000.

13. PENNEAU, J. La responsabilité médicale. Paris: Dalloz, 1977.

14. PIZAN, A.; VARGAS NETO, J.; JANSON, G. R. P. O paciente ortodôntico quanto ao seu grau de informação e motivação, e suas expectativas acerca do tratamento. Ortodontia, São Paulo, v. 30, n. 3, p. 40-44, set./dez. 1997.

15. PRUX, O. I. Um novo enfoque quanto à responsabilidade civil do profissional liberal. RPDC, Portugual, n. 6, p. 25-55, jun. 1996.

16. RAMOS, D. L. P. A ignorância do paciente quanto à dinâmica do tratamento odontológico: freqüente causa de conflitos jurídicos. J. APCD, São Paulo, v. 33, p. 497, set. 1998.
17. SANTOS, A. M. A obrigação do resultado do cirurgião dentista. Ortodontia, São Paulo. Disponível em: <http://www. odontologia.com.br/artigos>. Acesso em: 12 abr. 2005.

18. SCAFF, F. C. A responsabilidade do empresário pelo fato do produto e do serviço, do Código Civil ao Código de Proteção e Defesa do Consumidor. Rev. Trib., São Paulo, v. 737, p 23-33, 1997

19. SILVA, A. A.; MALACARNE, G. B. Responsabilidade civil do cirurgião dentista perante o Código de Defesa do Consumidor. JBO, Curitiba, v. 4, n. 22, p. 305-310, jul. 1999.

20. VENOSA, S. S. Direito civil: responsabilidade civil. 4. ed. São Paulo: Atlas, 2004. v. 4.

21. WHEELER, I. P. W. Risk preclusion. Am. J. Orthod. Dentofacial Orthop., St. Louis, v. 10, no. 2, p. 194-195, Feb. 1992.

22. ZART, R. E. Responsabilidade civil do cirurgião dentista. Jus. Navigandi, [s.l.], v. 7, no. 83, set. 2003. Disponível em: <http:// www.jus.com.br/doutrina/texto>. Acesso em: 14 abr. 2005.

23. KELSEN, H. Teoria geral das normas. Trad. José Florentino Duarte. Porto Alegre: Fabris, 1986.

24. KELSEN, H Teoria pura do Direito. Trad. Arménio Amado. 4. ed. Coimbra, 1976. 